\title{
Post-settlement movement of coral reef fishes and bias in survival estimates
}

\author{
Jennifer L. Frederick* \\ Department of Zoology, University of Hawaii, Honolulu, Hawaii 96822, USA
}

\begin{abstract}
Most coral reef fish have a bipartite life-history characterized by a pelagic larval phase followed by transformation and settlement into a benthic existence. There is increasing interest among marine ecologists in determining the importance of post-settlement processes to reef fish demography. This study distinguishes movement as an important post-settlement phenomenon affecting estımates of early survivorship of juvenile coral reef fishes. Individuals settling onto artificial patch habitats were collected, marked, released and monitored by visual census over 2 systems of isolated artificial patch habitats. Some recently settled juvenile fish moved as much as $100 \mathrm{~m}$ over open sand. Probability of movement was dependent on species; size was a significant factor among species, but not among conspecifics. Survivorship calculated from observations of uniquely marked individuals was contrasted with survivorship estimated by comparing the initlal number of newly settled individuals at a site with the number of individuals there after a given time interval. The comparison revealed that new settlers and immigrants can mask the loss of individuals included in the original census and thereby inflate estimates of survivorship. Comparing survival estimates with and without accounting for movement demonstrated that survivorship can be underestimated when new settlers subsequently emigrate and survive at another site, but are unwittingly recorded as lost due to mortality. Significant differences were observed in survival experiences for different species and size classes. Where significant differences were found in survival times of mobile individuals versus sedentary, those that moved survived longer.
\end{abstract}

KEY WORDS: Coral reef fishes - Recruitment Survival Mortality Movement - Artificial reefs

\section{INTRODUCTION}

Confronted with the discordant results drawn from 2 decades of ecological research, many marine ecologists now concede that no single factor model adequately explains the distribution and abundance of marine organisms with complex life histories. Rather, the cumulative effects of a number of interacting factors cause pre-settlement losses of larvae and post-settlement losses of juveniles (Doherty 1991, Jones 1991. Doherty \& Fowler 1994). For reef fishes, researchers have demonstrated that stochastic variation in larval success can affect recruitment strength (Williams \& Sale 1981, Sale et al. 1984a, Doherty 1987), but that high juvenile mortality can also modify recruitment patterns (Doherty \& Sale 1985, Victor 1986a, Eckert

\footnotetext{
-E-mail: jfrederiohpu.edu
}

1987, Shulman \& Ogden 1987, Meekan 1988, Robertson 1988, Sale \& Ferrell 1988)

There is continued interest among coral reef fish ecologists in evaluating the importance for early survivorship of the effects of post-settlement processes, e.g. predation (Carr \& Hixon 1995), ontogenetic habitat shifts (Lirman 1994, Eggleston 1995), habitat selection (Sweatman \& St. John 1990, Wellington 1992), habitat associations (Connell \& Jones 1991, Booth \& Beretta 1994), and intraspecific competition (Forrester 1990, 1995). A few researchers have inferred that early post-settlement movement of juveniles is an important process shaping observed patterns in juvenile abundance (Shulman 1985, Robertson 1988). However, few have attempted to directly measure movement of juveniles as an important post-settlement phenomenon that might affect estimates of early survivorship. Most studies designed to measure early survival of juveniles have assumed that significant losses from the study site 
were due to mortality, while losses due to emigration to other habitats were unlikely, or at most, negligible (Williams 1980, Aldenhoven 1986, Victor 1986a, Eckert 1987, Jones 1987a, b, 1988, Sale \& Ferrell 1988, Booth \& Beretta 1994). Yet when losses are due to movement. survival in some other habitat is possible and would have population consequences entirely different from mortality.

The primary obstacle in distinguishing post-settlement losses due to mortality from losses due to successful movement has been one of identifying individuals that have successfully moved. In attempts to overcome this obstacle, some researchers have implicitly used immigration rates to a study site as an estimate for emigration rates from a study site (Victor 1986a, Eckert 1987, Sale \& Ferrell 1988, Connell \& Jones 1991). Others have assumed that distances of open sand habitat ranging from a few meters (Williams \& Sale 1981, Sale et al. 1984b, Doherty 1987) to a few hundred meters (Carr \& Hixon 1995) were adequate to minimize successful movement from their study site (in most cases a natural or artificial patch reef) to other suitable habitats. Presumably, at sufficiently isolated sites, the effects of movement and local mortality are indistinguishable because any attempts at movement would end in mortality.

However, the minimum area of open sand habitat that 'sufficiently isolates' a patch habitat and prevents successful movement of juveniles has not been experimentally verified. Given the wide range of existing estimates of what distance of open sand minimizes successful movement, early survivorship may have been underestimated frequently at study sites from which fish moved successfully and survived at another site, but were erroneously recorded as lost due to mortality. If successful movement of early or late juveniles to other suitable habitat can moderate mortality or at least increase the probability of recruitment, it may be an important post-settlement process. Early post-settlement movement should be quantified in survivorship models rather than remain masked within 'mortality'

Many early mortality estimates based on net losses of fish from a study site over time may have been confounded by the appearance of new individuals indistinguishable from previously censused individuals. When individuals, or at least cohorts, cannot be distinguished, there is a high degree of uncertainty in survivorship estimates that are based on comparing the initial number of newly settled individuals with the number of individuals present after a known time interval. This is particularly critical when census intervals are short (e.g. daily) compared to the time scale over which developmental changes might allow individuals or at least cohorts to be distinguished.
This purpose of this study was to clearly demonstrate the movement capabilities of juvenile fishes between patch habitats by making direct field observations of marked individuals dispersing over an array of artificial reefs. Within the model system of artificial reefs, I tested 2 specific hypotheses: (1) survival can be underestimated when sucessful emigration from a study site to a new habitat is not accounted for in survivorship models; and (2) mortality can be underestimated when losses of individuals that are replaced between censuses by new, indistinguishable conspecifics remain undetected

\section{MATERIALS AND METHODS}

Movement between artificial patch reefs. To investigate movement patterns, 4 artificial reef clusters were deployed at 2 sand sites in Hanalei Bay, Kaua'i, Hawaii, isolated by at least $100 \mathrm{~m}$ or $350 \mathrm{~m}$ from the nearest natural or artificial reef and at a depth of approximately $10 \mathrm{~m}$. Underwater visibility varied from $<1 \mathrm{~m}$ to $15 \mathrm{~m}$. Artificial reef units were constructed of 4 orthogonally stacked and cemented concrete blocks (each block $10 \times 20 \times 40 \mathrm{~cm}$ with 2 holes $3 \times 15 \times 20 \mathrm{~cm}$ ). Polypropylene rope streamers were tied to the blocks and unraveled so that $1 \mathrm{~m}$ of fringe extended into the water column above the reef unit (as in Gorham \& Alevizon 1989). This design provided numerous small holes for safe refuge for juvenile fishes and yet was easy to census. Each cluster consisted of a central reef unit or units encircled equidistantly by evenly spaced perimeter reef units. Each of the 4 clusters differed in the radial distance of open sand between central and perimeter reefs (Fig. 1).

The first 2 clusters were assembled concurrently, with radii of $2 \mathrm{~m}$ or $5 \mathrm{~m}$, and were isolated by $100 \mathrm{~m}$ of sand habitat from each other and the nearest natural reef (Site I). Because substantial movement between clusters was observed, a new site isolated from the nearest natural reef by $350 \mathrm{~m}$ was chosen for the third and fourth clusters (Site II). These were assembled consecutively and had a radius of $50 \mathrm{~m}$, or 2 radii of 20 and $50 \mathrm{~m}$, respectively. For clusters with smaller radil (i.e. $2 \mathrm{~m}$ and $5 \mathrm{~m}$ ), adjacent outer reefs in a cluster were equidistant from the central reef and each other. Adjacent outer reefs of clusters with larger radii (i.e. $20 \mathrm{~m}$ and $50 \mathrm{~m}$ ) were spaced 10 to $20 \mathrm{~m}$ apart so that fishes moving in any direction were likely to encounter a suitable habitat (Fig 1).

Between 27 June and 30 August 1994, 286 recently settled fishes of 6 species from 8 to $57 \mathrm{~mm}$ standard length (SL) (Table 1) were collected from all perimeter reef units, individually marked using fluorescent elastomer injection (Frederick in press), and released at 


\section{SITE I}

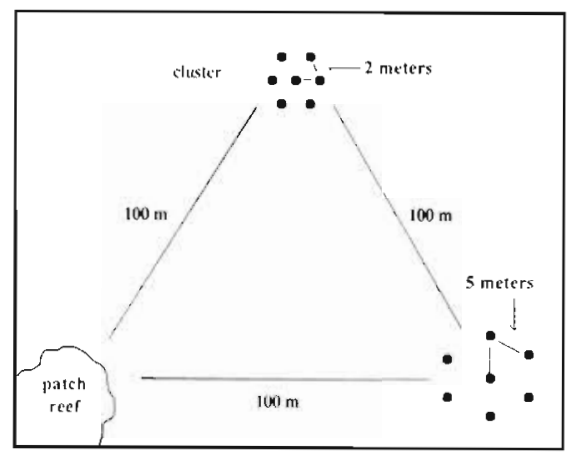

\section{SITE II}

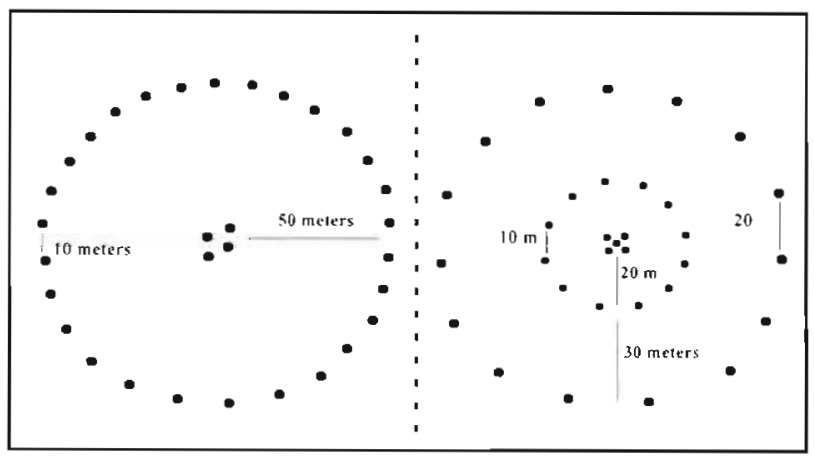

Fig. 1 Artificial reef site configurations in Hanalei Bay. Two clusters of artificial reefs ( $2 \mathrm{~m}$ or $5 \mathrm{~m}$ radul isolated by $100 \mathrm{~m}$ from each other and the nearest natural reef were monitored simultaneously at Site I. Two clusters $150 \mathrm{~m}$ or 20 and $50 \mathrm{~m}$ radii) 1 solated by at least $350 \mathrm{~m}$ from any other reef were monitored consecutively at Site II the central reef units to a maximum density of 70 fish (mean $=41$ fish). At Site I, fishes were collected within $8 \mathrm{~d}$ of colonizing the reefs; at Site II fishes were collected within $2 \mathrm{~d}$ of colonizing the reefs, many of these fish having little or no pigmentation. Movement and survivorship of marked juveniles were monitored by visual census of all reef units in the artificial reef clusters at daily intervals (or as often as feasible). Regular observation periods for individuals ranged from 2 to $48 \mathrm{~d}$; some individuals were censused after the completion of the study up to 133 d after release. The fate of each marked individual was recorded: survival on the central reef unit, movement to a perimeter reef unit, or assumed mortality if it could not be located on the reef cluster Because individuals could have emigrated beyond the radius of the experimental reef clusters and survived on natural reefs more than $100 \mathrm{~m}$ or $350 \mathrm{~m}$ away, reported survival is a minimum estimate.

Analysis of survival data. Analysis of survival data required several special considerations. First, survival measurements were confounded by time. That is, whether or not death was observed was influenced by the length of the observation period for the individual and the conditions during that period. Because new individuals were continually added to the study and were followed over various time intervals, the period that each individual was followed was taken into account by stratifying the analysis by the shortest time interval over which differences in survival were measured (daily). Second, over $40 \%$ of the fishes outlived the study. This led to right-censored observations;

Table 1. At each site for each species of fish used in movement experiments, total number of individuals marked, number lost from study area during period of monitoring, mean, minimum and maximum size ( $\mathrm{mm}$ SL), and proportion of all individuals marked and released on a cluster with a given radius that were observed to make at least one movement. Distances are meters traveled over open sand between patch habitats. The category $20 \mathrm{~m}$ includes movements observed between the central reefs and the $20 \mathrm{~m}$ inner ring and between the central reefs and the $50 \mathrm{~m}$ outer ring of the cluster with both radii. Thus, the conservative assumption was made that movements to the outer ring were made in a stepping stone progression

\begin{tabular}{|c|c|c|c|c|c|c|c|c|}
\hline \multirow[t]{2}{*}{ Family } & \multirow[t]{2}{*}{ Species } & \multirow[t]{2}{*}{ Total } & \multirow[t]{2}{*}{ Lost } & \multicolumn{2}{|c|}{ Size (mm SL) } & \multicolumn{3}{|c|}{ Movements } \\
\hline & & & & Mean $\pm \mathrm{SD}$ & Min - max & $2 \mathrm{~m}$ & $5 \mathrm{~m}$ & $100 \mathrm{~m}$ \\
\hline \multicolumn{9}{|l|}{ Site I } \\
\hline Acanthundae & Acanthurus blochii & 9 & 7 & $43 \pm 2.3$ & $40-48$ & $0 / 0$ & $9 / 9$ & $0 / 9$ \\
\hline Apogonidae & Apogon sp. & 4 & 4 & $14 \pm 7.1$ & $9-24$ & $0 / 3$ & $0 / 1$ & $1 / 4$ \\
\hline Pomacentridae & Dascyllus albisella & 14 & 13 & $15 \pm 5.1$ & $8-21$ & $1 / 6$ & $4 / 8$ & $0 / 14$ \\
\hline Chaetodontidae & Heniochus diphreutes & 22 & 8 & $43 \pm 2.4$ & $38-47$ & $5 / 5$ & $17 / 17$ & $3 / 22$ \\
\hline \multirow[t]{2}{*}{ Lutjanidae } & Lutjanus kasmira & 5 & 4 & $46 \pm 4.5$ & $40-52$ & $0 / 0$ & $5 / 5$ & $2 / 5$ \\
\hline & & & & & & \multicolumn{2}{|l|}{$20 \mathrm{~m}$} & $50 \mathrm{~m}$ \\
\hline \multicolumn{6}{|l|}{ Site II } & \multirow{2}{*}{\multicolumn{2}{|c|}{$0 / 40$}} & $3 / 47$ \\
\hline \multirow[t]{2}{*}{ Chaetodontidae } & $\begin{array}{l}\text { Acanthurus blochin } \\
\text { Chaetodon miliaris }\end{array}$ & $\begin{array}{l}87 \\
14\end{array}$ & $\begin{array}{r}65 \\
7\end{array}$ & $\begin{array}{l}32 \pm 6.9 \\
26 \pm 2.1\end{array}$ & $\begin{array}{l}20-42 \\
22-31\end{array}$ & & & $1 / 14$ \\
\hline & Heniochus diphreutes & 71 & 34 & $38 \pm 5.9$ & $26-57$ & \multicolumn{2}{|l|}{$0 / 43$} & $0 / 28$ \\
\hline Lutjanidae & Lutjanus kasmira & 60 & 26 & $32 \pm 3.8$ & $20-38$ & \multicolumn{2}{|l|}{$25 / 44$} & $1 / 16$ \\
\hline
\end{tabular}


that is, the outcome for these individuals was unknown. Omitting these data would underestimate survival, because it was usually the most long-lived individuals that were right-censored. To take into account the time that these individuals were alive, without knowing the exact time of death, I computed survival as a cumulative probability function: probability of survival over the time interval given that the individual had survived up until that time interval (Lee 1992). Finally, survival data did not follow a normal distribution, because of the high early mortality (Type III mortality curve) typical of many marine animals. I used the SAS procedure LIFETEST, which can analyze survival data involving these sorts of special considerations (SAS 1990).

To examine survival as it varied among species, sites, mobile versus sedentary individuals and size classes, I used a modified non-parametric log rank test (MantelHaenszel procedure) with time stratified by day (Everitt 1994). This test compares the observed number of deaths occurring among groups at each particular time point with the number expected if the survival experiences of the groups were the same. It is fairly robust to a non-constant hazard ratio (age-specific mortality rate), which frequently occurs when time of origin in a treatment is not the same and when censoring occurs (Pyke \& Thompson 1986).

\section{RESULTS}

\section{Movement between artificial patch reefs}

Movement between patch reefs was observed for all 6 species. Over all species and cluster configurations, approximately $25 \%$ of marked fishes were observed to move at least once over distances of open sand ranging from 2 to $100 \mathrm{~m}$ (Table 1 ). Of the 41 individuals that moved, approximately $30 \%$ made multiple movements. Some were observed to move 3 or 4 times, most often back to reefs that they had already visited. Four additional $100 \mathrm{~m}$ movements were observed for the butterflyfish Heniochus diphreutes: 1 individual moved between reef clusters twice, and 3 other individuals moved to the $5 \mathrm{~m}$ cluster after their $2 \mathrm{~m}$ cluster was dismantled. Fifteen additional movements were observed for the snapper Lutjanus kasmira representing repeated movements of 9 individuals over distances of 10,20 and $30 \mathrm{~m}$.

\section{Factors associated with movement}

Probability of movement was dependent on species (Fisher's exact test, $\mathrm{n}=286, \mathrm{p}<0.001$ ) (Table 1 ). How-

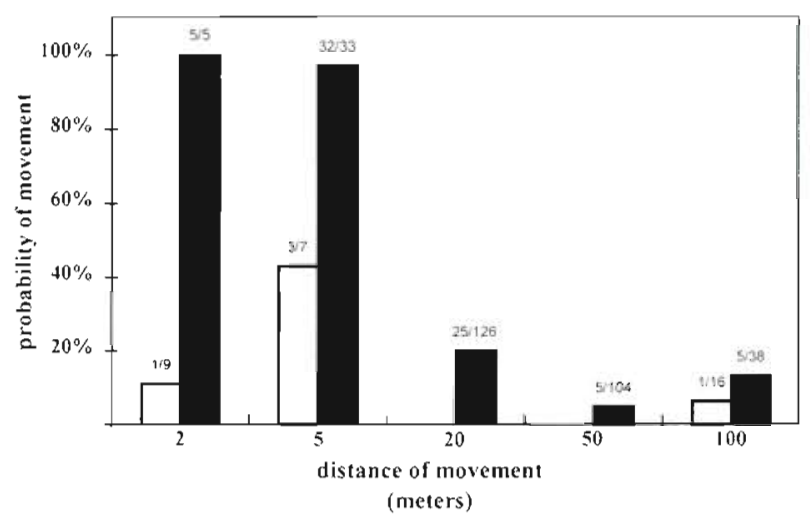

Fig. 2. For 2 size classes, probability of movement over a given distance of open sand between patch habitats (radii of reef clusters). Probabilities represent the percent of all individuals marked and released on a cluster with a given radius that were observed to make at least one movement. Size classes are $\leq 20 \mathrm{~mm}$ SL (white bars) and $>20 \mathrm{~mm}$ SL (black bars). The distance $20 \mathrm{~m}$ includes movements observed between the central reefs and the $20 \mathrm{~m}$ inner ring and between the central reefs and the $50 \mathrm{~m}$ outer ring of the cluster with both radii. This accomodates the conservative assumption that movements to the outer ring were made in a stepping-stone progression. No data are available for fishes $\leq 20 \mathrm{~mm}$ SL moving $20 \mathrm{~m}$ or $50 \mathrm{~m}$

ever, at Site I ( $2 \mathrm{~m}$ and $5 \mathrm{~m}$ radii clusters), the species effect was confounded by fish size. Most fishes $\leq 20 \mathrm{~mm}$ SL were apogonids and pomacentrids, and most fishes $>20 \mathrm{~mm}$ SL were acanthurids, chaetodontids, and Iutjanids. Species of the smaller size class moved less frequently than those of the larger (Fisher's exact test, $\mathrm{n}=54, \mathrm{p}<0.001$ ) (Fig 2). For mobile fishes $>20 \mathrm{~mm}$ SL (acanthurids, chaetodontids, lutjanids), larger individuals traveled longer distances (Kendal's tau $=0.317, n=35$, normal approximation $p=0.004$ ) Pomacentrids and apogonids were not included in this test because none were monitored at Site II $(20 \mathrm{~m}$ and $50 \mathrm{~m}$ radii clusters), where potentially longer movements could have been measured. Among conspecifics, there was no significant difference in sizes (SL) of mobile and sedentary individuals (Rank sum tests, $p>0.17$, except among Dascyllus albisella, $p=$ 0.083). The weakly significant difference for $D$. albisella may be due to lower overall survival for smaller individuals that resulted in less opportunity for movement.

\section{Factors associated with survival}

The survival experiences of the 6 species in this study were significantly different [Mantel-Haenszel (log rank) test, $p=0.0001$ ]; therefore, further analysis was stratified by species. Survival data from Sites I and 
II were pooled for analysis, because no significant differences in survival time were found for species measured at the 2 sites $(p \geq 0.16$ ). For 4 species, there was no significant difference in the survival time of mobile versus sedentary individuals $(p \geq 0.18)$. Where more significant differences were found (Apogon sp. $\mathrm{p}=$ 0.08; Dascyllus albisella $\mathrm{p}=0.0006$ ), mobile individuals survived longer than those that remained sedentary. Acanthurus blochi, Heniochus diphreutes and Lutjanus kasmira showed highly significant differences in survival between size classes ( $p<0.001)$. Other species showed no differences $(p>0.4)$. Where significant differences were found, smaller size classes generally showed lower survival. Among fishes that moved, there were no significant differences in survival (1) by distance of movement $(p>0.3)$ or (2) by the time between release and movement $(p>0.8)$.

\section{Survival estimates and the effect of successiul movement}

Using results of repeated censuses of the clusters, survivorship was calculated using 2 models. The first model (Model 1) provided a survival rate based on the losses of marked fishes from the central reef over time. By attributing all losses to mortality and ignoring movement, Model 1 underestimated survivorship. The second model (Model 2) used the marking program to allow recognition of migrators, whose survival could be measured after emigration from the central reef Model 2 produced more accurate survival rates, because real mortality was not inflated by losses due to movement. Non-parametric estimates of Model 1 and Model 2 survival functions were generated using the life table method of SAS LIFETEST. Comparing the curves for each species observed to move within or between reef clusters at Site I (Fig. 3) and within clusters at Site II (Fig. 4) demonstrates the importance of movement as a source of post-settlement loss.

The blue-striped snapper Lutjana kasmira demonstrated the greatest tendency for post-settlement movement. After $8 \mathrm{~d}$ of observations at Site I (Fig. 3B), survival was twice as high in the model which included individuals moving $100 \mathrm{~m}$ (Model 2), a difference maintained through Day 35 of observations. At Site II (Fig. 4A), where $43 \%$ of $L$. kasmira emigrated 20,30 or $50 \mathrm{~m}$ from the central census site, survival was about twice as great in Model 2 for most of the $48 \mathrm{~d}$ period of observations.

The Hawaiian domino damselfish Dascyllus albisella was the smallest species studied; marked individuals were as small as $8 \mathrm{~mm}$ SL. Unlike other fishes in this study, young $D$. albisella remained inconspicuously hidden within holes of the reefs during censusing and were not observed to roam far from shelter. However, movement of marked individuals between patch reefs did occur, creating striking differences in survival curves. Half of all fish marked at the $5 \mathrm{~m}$ radius cluster moved from the central reef to a perimeter reef; only 1 of 6 fish moved at the $2 \mathrm{~m}$ radius cluster, but overall survival was very low. Without knowledge of these movements, survival would appear to plummet to zero after only $4 \mathrm{~d}$ (Fig. 3C), when in fact survival was greater than zero for at least $35 \mathrm{~d}$.
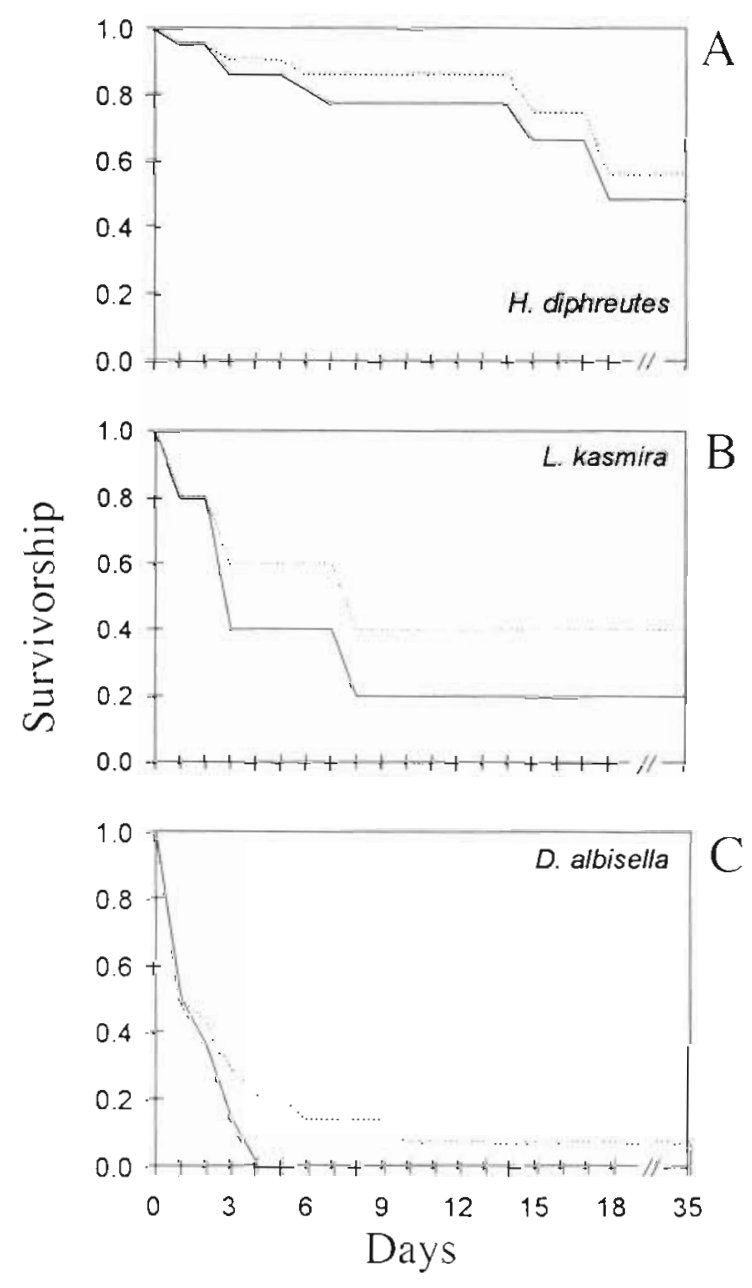

Fig. 3. Survival for 3 species at Site I. Model $1(-\square)$ is the survival estimate based on losses from the central reefs. Model $2(\cdots)$ is the survival estimate based on losses of individuals over the entire site and includes survival of mobile individuals. Differences between Model 1 and Model 2 survivorship represent the survival of individuals moving $100 \mathrm{~m}$ between reef clusters for Heniochus diphreutes (A) and Lutjanus kasmira (B), which schooled freely over the 2 and $5 \mathrm{~m}$ radius clusters. For Dascyllus albisella $(\mathrm{C})$, the difference between Model 1 and Model 2 survivorship represents the survival of individuals moving $2 \mathrm{~m}$ or $5 \mathrm{~m}$ within clusters. Number of migrators: $A=3, B=2, C=5$. Total number of individuals monitored: $A=22, B=5, C=14$ 

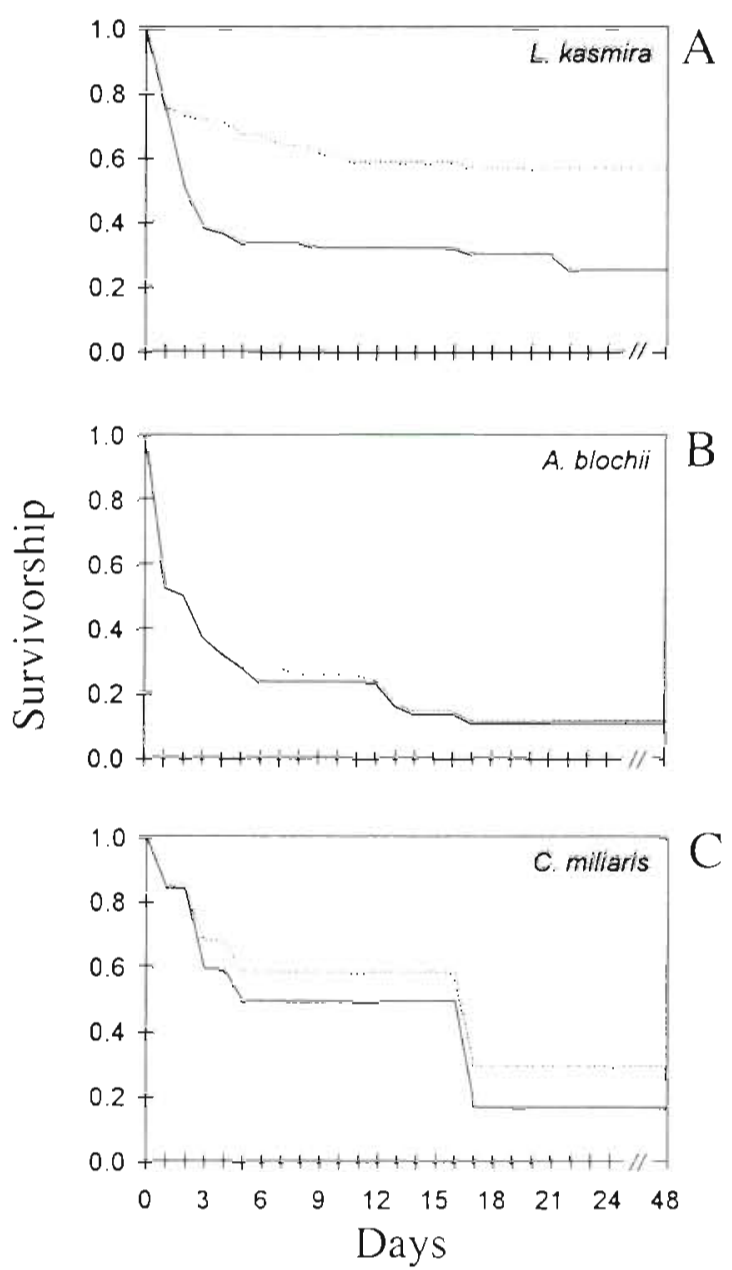

Fig. 4. Survival for 3 species at Site II. Model $1(\longrightarrow)$ is the survival estimate based on losses from the central reefs. Model $2(\cdots \cdots)$ is the survival estimate based on losses of individuals over the entire site and includes survival of individuals moving $20 \mathrm{~m}$ or $50 \mathrm{~m}$. Number of migrators: $A=26$, $\mathrm{B}=3, \mathrm{C}=1$ Total number of individuals monitored: $\mathrm{A}=60$,

$$
\mathrm{B}=87, \mathrm{C}=14
$$

\section{Mortality estimates and the effect of undetected loss and replacement}

To measure the bias in mortality estimates from new indistinguishable colonizers replacing previously censused individuals, the population flux at the central reefs of the clusters at Site II was monitored by repeated censuses. At each census, loss from the central reef for the period between censuses was estimated by 2 methods: net loss and actual loss. Net loss was computed as the difference between a count of the total number of individuals present on the central reef and the count of the previous census. Because this method did not keep track of individuals, it did not distinguish new individuals that had colonized between censuses. Net loss was contrasted with actual loss, which was computed as the number of marked individuals that were present on the central reef at the previous census and absent at the current census.

A comparison of the 2 'mortality rates' showed that unrecognized new colonizers could replace previously censused individuals and mask actual losses. In $74 \%$ of censuses where actual loss of marked individuals was measured, riet loss underestimated actual loss (Fig. 5). For censuses where net loss was less than actual loss, replacement of previously censused fish by new fish would have gone undetected but for the marking of individuals. In other cases, when colonization numbers were large, resulting in an apparent net gain of fish, replacement would likely have been suspected. However, without accurate identification of individuals, the total amount of mortality that had occurred between censuses would remain unknown. Neither net loss nor actual loss in the examples of Fig. 5 is corrected for successful, monitored emigrations from the central reef to perimeter reefs (as in Figs. $3 \& 4$ ).

\section{Evaluation of effects of marking and transplantation on movement patterns}

All newly marked fish were held and observed underwater for 2 hours before release. Based on laboratory observations, signs of imminent mortality (e.g. increased reaction time and loss of equilibrium) could be detected within that time (Frederick in press). Among fishes $>20 \mathrm{~mm} \mathrm{SL}(\mathrm{n}=270)$, no signs of stress or imminent mortality were observed. For fishes $<20 \mathrm{~mm}$ SL ( $n=16), 2$ individuals appeared negatively affected and were assumed to have died shortly thereafter. This level of mortality was not significantly greater than zero (Fisher's exact test; 1-sided, $p=0.276$ ). In this experiment, designed to test for emigration by marking and monitoring individuals, it would not have been possible to accurately identify and follow a control group of unmarked fishes.

Transplantation is commonly employed to manipulate densities of individuals on artificial reefs to examine various post-settlement processes. Some investigators report little difficulty in getting transplants to remain on their host reefs (Jones $1987 \mathrm{a}$, Forrester 1990, 1995, Booth 1991) and no significant differences in the permanence of transplants versus controls (Lirman 1994, Carr \& Hixon 1995). Others report spontaneous emigration by pomacentrids, which required repeat transplantation (Ebersole 1985, Jones 1987b, 1988 ) or special measures to prevent emigration (Sweatman 1985b). The time to first observed movement after manipulation and release was examined to identify possible spontaneous emigration. Immediately 
Fig. 5. Losses at the central reefs of Site II measured by 2 methods net losses and actual losses. Black bars track net losses calculated as the change in number of fishes on the central rent from une census to the next. Positive values indicate that apparent losses exceeded colonizations (net loss); negative values indicate that colonizations exceeded apparent losses (net gain). White bars track actual losses from the central reef from one census to the next, based on disappearance of marked individuals from the central reef, and thus are always positive. Net losses underestimate actual losses in all censuses where the 2 measures diverge. Positive black bars alone are where the 2 estimates are equal (i.e. the black bar masks the white bar of equal size)

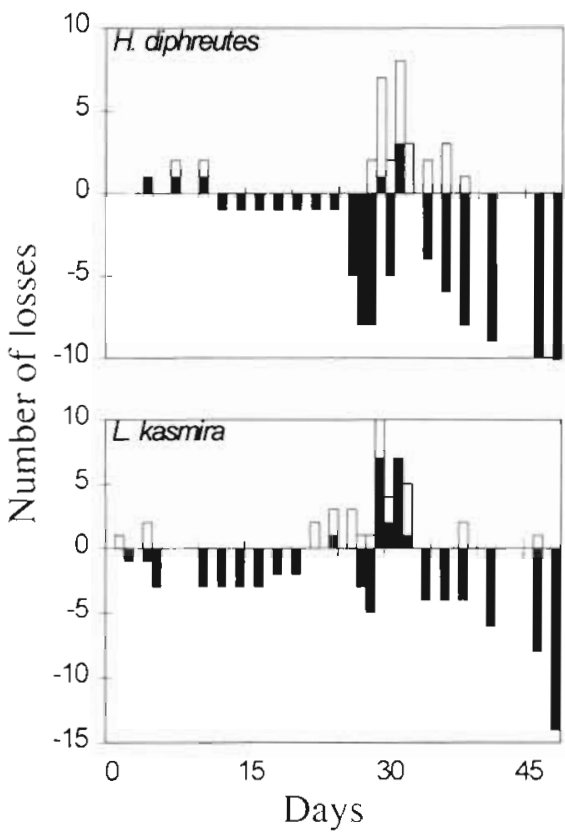

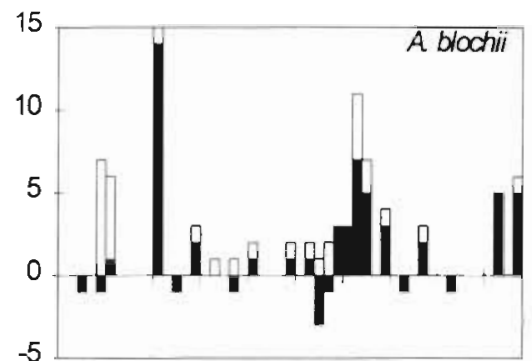

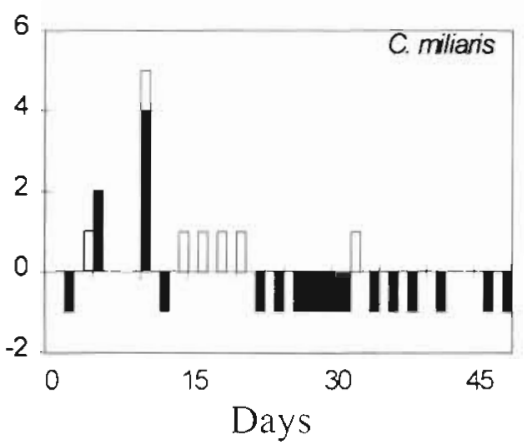

upon release, fish were observed to seek shelter within the artificial reef structures or join existing groups which remained very close to the reefs $(\sim 1$ to $2 \mathrm{~m})$. Only the snapper Lutjana kasmira showed a strong tendency to move soon after release. Of 28 individual L. kasmira that left the central reefs, 15 did so within the first day and 8 more within the second day after release. However, $40 \%$ of these migrators were observed to make up to 3 additional movements within the next $18 \mathrm{~d}$. The majority of first movements of other species occurred within 5 to $9 \mathrm{~d}$ post-release; a third of individuals leaving the central reefs soon after release (within 2 d) made further movements.

Non-random movement of a fish from its post-transplant reef directly toward its pretransplant reef (home reef) could indicate a homing behavior released by the manipulation. The net direction of all movements prior to the first census after transplantation to the central reefs at Site II was examined using circular statistics (Batschelet 1981) Direction of movement was significantly correlated with the bearing of an individual's home reef (circular rank correlation $r^{2}=0.24, n=29,0.01<p<$ $0.05)$, indicating that fish dispersed nonrandomly with respect to their home reef (Fig. 6). However, the correlation between direction of emigration and bearing of home reef may be confounded by other factors. An analysis of the overall colonization and dispersal patterns over Site II also revealed non-uniform patterns (Rayleigh test for circular uniformity, $\mathrm{n}=231$, $p<0.001$, and $n=29, p<0.005$, respectively)
(Fig 7 A, B). Mean angles for settlement and dispersal were in the west/northwest quadrant of the reef cluster. Some environmental factor(s) may have cued colonizers and migrators in a general west/northwest direction (e.g. wind and surface water currents flowed across the site in this general direction; the closest large natural reefs were in this direction). These results suggest that the observed emigrations of all species from the central reefs may represent their natural tendencies and are not an artifact of the transplantation procedure.

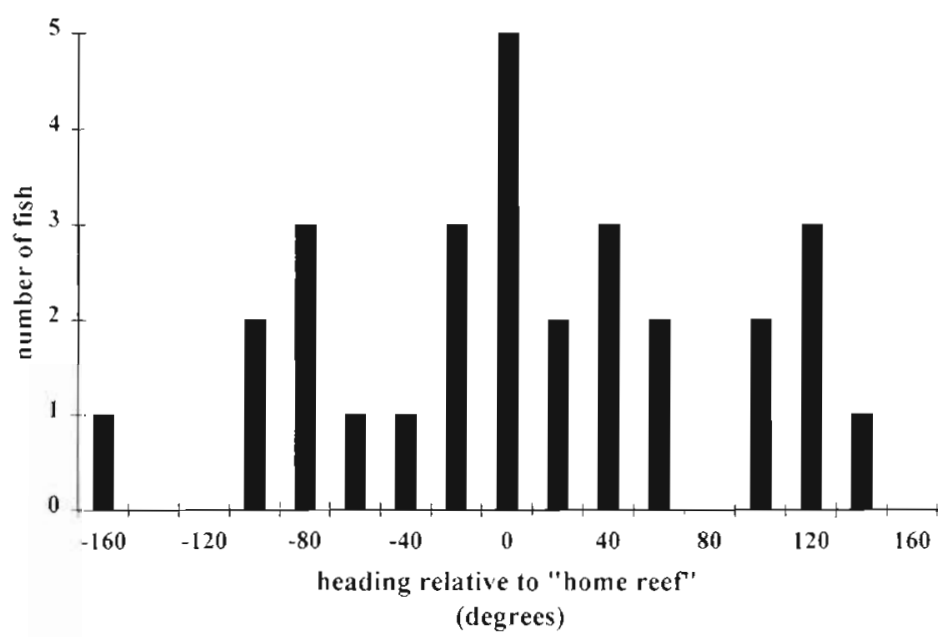

Fig. 6. Number of fish and directional headings of first observed movement in degrees relative to place of collection (home reef) for fish moving from the central reefs to perimeter reefs (i.e. compass bearing of collection reef minus compass bearing of destination reef). Fish moving at a heading of $0^{\circ}$ returned to place of collection 

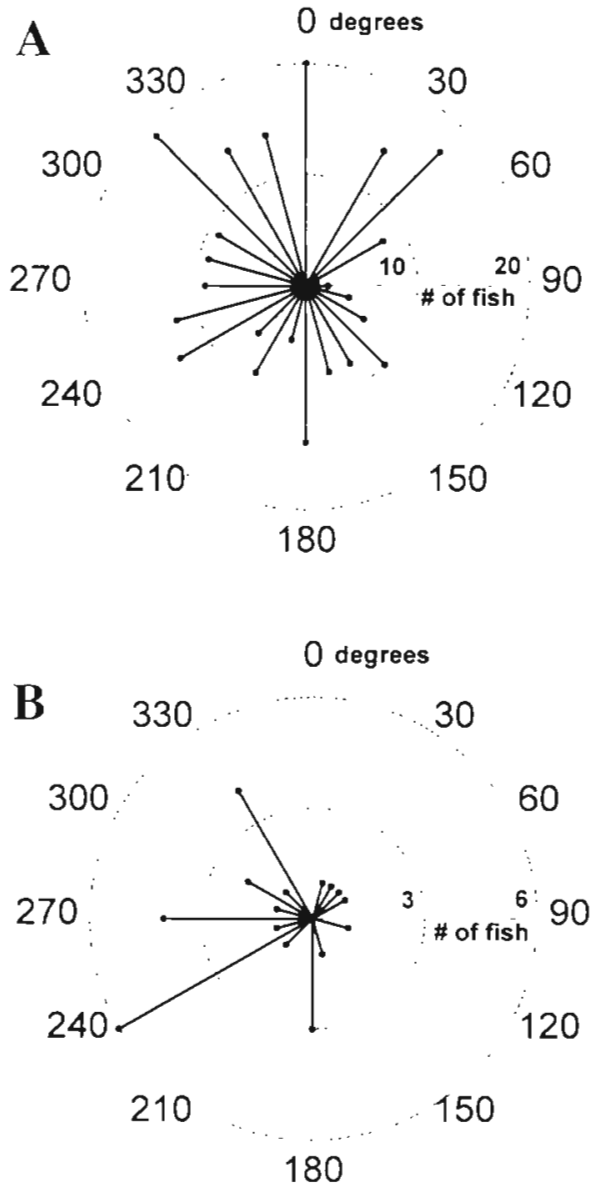

Fig. 7. (A) Number and angular distribution of fish initially colonizing artificial patch reefs at the perimeter of Site II. Dispersion is indicated by compass bearings of perimeter reefs from the center of the circular cluster. Length of rays extending from center are scaled by frequency. (B) Number of fish and directional headings of destination reefs after dispersal from central reef site to perimeter reefs at Site II

\section{DISCUSSION}

A large part of the research on early post-settlement processes of coral reef fishes has been conducted with pomacentrids on patch reefs, in part because of their presumed sedentary nature. Although the results obtained in this study are based on limited sample sizes of only 1 species of damselfish, they suggest that early survival of pomacentrids may often have been underestimated because of undetected movements (Jones 1987a, b, 1988, Sale \& Ferrell 1988, Booth \& Beretta 1994). At least 2 studies exist in which movement of pomacentrids has been directly observed. In a study of Dascyllus albisella, Booth (1991) marked 30 new recruits (10 to $15 \mathrm{~mm} \mathrm{SL}$ ) by fin clipping and transplanted them to an array of artificial reefs. One movement was observed between reefs $10 \mathrm{~m}$ apart in a
$5 \times 12$ grid of 60 small coral heads, but many marked fish were never resighted. Forrester (1990) manipulated $D$. aruanus juveniles on an array of artificial reefs and measured a $2 \%$ movement rate between reefs 20 to $25 \mathrm{~m}$ apart. Only juveniles that had grown larger than $25 \mathrm{~mm}$ fork length (FL) were marked for individual identification

Post-settlement movements by juveniles of other taxa are largely unconfirmed in the literature. Brock et al. (1979) inferred substantial post-settlement movement from a recolonization experiment on a patch reef in Kane'ohe Bay, Hawaii, isolated from other reefs by $120 \mathrm{~m}$. The majority of fishes colonizing the patch reef were juveniles well beyond transformation, indicating that they had not arrived from the plankton. In a study of abundances of surgeonfishes on patch reefs in the Caribbean, Robertson (1988) suggested that for some patch reefs receiving few new settlers but supporting large populations of larger size classes, relocation some time after settlement may be the primary source of recruits. Mortality of labrids in the Caribbean and Great Barrier Reef (Victor 1986a, Eckert 1987) was studied on reefs isolated by $10 \mathrm{~m}$ of sand or seagrass from other suitable habitats. At both sites, negligible emigration was inferred, because no immigration was observed. Based on estimates of low immigration rates to a temperate reef population of blennies Forsterygion varium, Connell \& Jones (1991) also inferred that emigration was negligible for new recruits up to 2 mo postsettlement. Forrester (1995) observed movement of marked Caribbean gobies Coryphopterus glaucofraenum between natural and artificial reefs located at least $8 \mathrm{~m}$ from any other reef, but apparently the event was rare. Results reported here of acanthurids, chaetodontids, and lutjanids moving at least $50 \mathrm{~m}$ and sometimes $100 \mathrm{~m}$ confirm the possibility that early post-settlement movement occurs with some frequency among some common coral reef species.

The demonstrated ability of coral reef fishes to make successful early post-settlement movements between patch habitats has important implications. To determine more accurately how survival of juvenile coral reef fishes is affected by post-settlement processes, we must study the fate of individuals on a larger spatial scale than previously. Knowledge of juvenile movement patterns aids in performing repeated visual census of juveniles over large reef areas where an observer could predict the home range of a particular species at a particular age. Especialiy when the application of a marking technique may be undesirable or not feasible, recensusing individuals or cohorts based on an a priori estimate of their home range can facilitate studying other early life history characteristics. It would also help in designing closed system juvenile demographic studies which utilize systems of patch reefs 
The results of this research suggest that for studies of early survival for which emigration from the census area has remained unaccounted, survival may have been underestimated. This research has shown that individuals can survive and persist after moving at least $100 \mathrm{~m}$ to a new site and have a positive effect on survival estimates at least as long as those that remain sedentary. Estimates of survival may have been further confounded by arrival of undetected new colonizers. Mortality rates based on net losses of fish between censuses are common in the literature (Victor 1986a, Eckert 1987), probably because until recently no suitable marking method was available. Based on the present demonstration, early mortality reported can be underestimated due to unrecognized loss and replacement by settlement or immigration. These 2 processes unobserved migrations and unobserved settlement and replacement-probably create bias in survival estimates simultaneously, so that a wide range of net errors is possible. The observations of this study illustrate the potential effects in a model system. The magnitude of error is probably dependent on strength of local settlement pulses, local predation rates, habitat quality, the frequency of movement, and the time elapsed between censuses.

Making a movement between habitats presents risks to survival, both in the hazards of the journey to another habitat and in the suitability of that destination. It may be assumed that post-settlement movements would only be beneficial if the risk to survival induced by leaving is less than the potential loss of fitness incurred by staying in a habitat with strong negative effects. Therefore, the prevalence of successful post-settlement movement may be an indicator of the relative risks associated with predation and the suitability of various alternative habitats, and thus may be site-specific. Although this study did not attempt to assign motive for the observed movement, it does imply that juvenile coral reef fishes may be equipped with the behavioral flexibility to exercise habitat choice shortly after settlement. Habitat sampling may be a life history tactic for juvenile fish and may confer an advantage to species that make frequent post-settlement movements.

Perhaps marine ecologists have underestimated the abilities of newly settled coral reef fishes. The most recent work of fish biologists suggests that young reef fish have great developmental and behavioral flexibility. While still in the plankton, they may be able to slow their growth and sustain periods of active swimming until suitable settlement habitat is encountered (Victor 1986b, Cowen 1991, Stobutzki \& Bellwood 1994). Upon settlement, juvenile fishes have exhibited diel behavioral patterns, sensory cueing and habitat choice (Eckert 1985, Sweatman 1985a, 1988, Sweatman \& St. John
1990, Wellington 1992). In fact, Kaufman et al. (1992) used the term 'transition phase' to describe the sequence of events bridging the late larval and early juvenile periods, and suggested that the importance of these events as determinants of population structure has been underestimated. Ontogenetic migration of late juvenile coral reef fishes from sea grass beds and/or mangroves to adjacent reefs is a well-known mechanism for their successful recruitment to adult populations (Shulman 1985, Robertson \& Duke 1987, Ogden 1988, Rooker \& Dennis 1991, Lirman 1994, Eggleston 1995). If intense competition or local disturbance such as predation or habitat destruction is encountered soon after settlement to the reef, the ability to make early post-settlement movements to alternative habitat would be adaptive.

Acknowledgements. This work benefited from the insightful comments of J Parrish, R. Kinzie, K. Holland, M. Hixon, R. Buckley and $J$ Orr, and the patient field assistance of R. DeFelice, A. Friedlander, J. Peterson and L. Ross. Sage statistical advice was offered by A. Taylor, R. Buckley graciously provided technical advice on the marking methodology, and D. Shafer provided unlımited support and encouragement. J. Glynn and the staff at the Hanalei site of the Kauai National Wildlife Refuge Complex, U.S. Fish and Wildlife Service, were helpful and accommodating in providing logistic support. Northwest Marine Technology, Inc., Shaw Island, Washington, generously supplied the marking materials. Partial funding was provided by the Hawail Cooperative Fishery Research Unit through a grant to J Parrish from the Hawali Department of Land and Natural Resources, Division of Aquatic Resources.

\section{LITERATURE CITED}

Aldenhoven AJ (1986) Local variation in mortality rates and life-expectancy estimates of the coral reef fish Centropyge bicolor. Mar Biol 92:237-244

Batschelet E (1981) Circular statistics in biology. Academic Press, London

Booth DJ (1991) The effects of sampling frequency on estimates of recruitment of the domino damselfish Dascyllus albisella Gill. J Exp Mar Brol Ecol 145:149-159

Booth DJ, Beretta GA (1994) Seasonal recruitment, habitat associations and survival of pomacentrid reef fish in the US Virgin Islands. Coral Reefs 13:81-89

Brock RE, C Lewis, Wass RC (1979) Stability and structure of a fish community on a coral patch reef in Hawaii. Mar Biol 54:281-292

Carr MH, Hixon MA (1995) Predation effects on early postsettlement survivorship of coral-reef fishes. Mar Ecol Prog Ser 124:31-42

Connell SD, Jones GP (1991) The influence of habitat complexity on postrecruitment processes in a temperate reef fish population. J Exp Mar Biol Ecol 151:271-294

Cowen RK (1991) Variation in the planktonic larval duration of the temperate wrasse Semicossyphus pulcher. Mar Ecol Prog Ser 69:9-15

Doherty PJ (1987) The replenishment of populations of coral reef fishes, recruitment surveys, and the problems of variability manifest on multiple scales. Bull Mar Sci 41 $411-422$ 
Doherty PJ (1991) Spatial and temporal patterns in recruitment. In: Sale PF (ed) The ecology of fishes on coral reefs. Academic Press, San Diego, p 261-293

Doherty PJ, Fowler T (1994) An empirical test of recruitment limitation in a coral reef fish. Science 263:935-939

Doherty PJ, Sale PF (1985) Predation on juvenile coral reef fishes: an exclusion experiment. Coral Reefs $4: 225-234$

Ebersole JP (1985) Niche separation of two damselfish species by aggression and differential microhabitat utilization. Ecology 66:14-20

Eckert GJ (1985) Settlement of coral reef fishes to different natural substrata and at different depths. Proc 5th Int Coral Reef Congr 5:385-390

Eckert GJ (1987) Estimates of adult and juvenile mortality for labrid fishes at One Tree Reef, Great Barrier Reef. Mar Biol 95:167-171

Eggleston DB (1995) Recruitment in Nassau grouper Epinephelus striatus: post-settlement abundance, microhabitat features, and ontogenetic habitat shifts. Mar Ecol Prog Ser $124: 9-22$

Everitt BS (1994) Statistical methods for medical investigations, 2nd edn. Halsted Press, New York

Forrester GE (1990) Factors influencing the juvenile demography of a coral reef fish. Ecology 71:1666-1681

Forrester GE (1995) Strong density-dependent survival and recruitment regulate the abundance of a coral reef fish. Oecologia 103:275-282

Frederick JL (in press) Evaluation of fluorescent elastomer injection as a method for marking small fish. Bull Mar Sci 60

Gorham JC, Alevizon WS (1989) Habitat complexity and the abundance of juvenile fishes residing on small scale artificial reefs. Bull Mar Sci 44:662-665

Jones GP (1987a) Competitive interactions among adults and juveniles in a coral reef fish. Ecology 68:1534-1547

Jones GP (1987b) Some competitive interactions between residents and recruits in two coral reef fishes. J Exp Mar Biol Ecol 114:169-182

Jones GP (1988) Experimental evaluation of the effects of habitat structure and competitive interactions on the juveniles of two coral reef fishes. J Exp Mar Biol Ecol 123: $115-126$

Jones GP (1991) Postrecruitment processes in the ecology of coral reef fish populations: a multifactorial perspective. In: Sale PF (ed) The ecology of fishes on coral reefs. Academic Press, San Diego, p 294-328

Kaufman L, Ebersole J, Beets J, McIvor CC (1992) A key phase in the recruitment dynamics of coral reef fishes: post-settlement transition. Environ Biol Fish 34:109-118

Lee ET (1992) Statistical methods for survival data analysis, 2nd edn. John Wiley and Sons, New York

Lirman D (1994) Ontogenetic shifts in habitat preferences in the three-spot damselfish, Stegastes planifrons (Cuvier), in Roatan Island, Honduras. J Exp Mar Biol Ecol 180: $71-81$

Meekan MG (1988) Settlement and mortality patterns of juve. nile reef fishes at Lizard Island Northern Great Barrier Reef. Proc 6th Int Coral Reef Symp 2:779-784

Ogden JC (1988) The influence of adjacent systems on the structure and function of coral reefs. Proc 6th Int Coral Reef Symp 1:123-129

Pyke DA, Thompson JN (1986) Statistical analysis of survival and removal rate experiments. Ecology 67:240-245

This article was presented by K. Sherman (Senior Editorial Advisor), Narragansett, Rhode Island, USA
Robertson AI, Duke NC (1987) Mangroves as nursery sites: comparisons of the abundance and species composition of fish and crustaceans in mangroves and other nearshore habitats in tropical Australia. Mar Biol 96:193-205

Robertson RD (1988) Abundances of surgeonfishes on patchreefs in Caribbean Panama: due to settlement, or postrecruitment events? Mar Biol 97:495-501

Rooker JR, Dennis GD (1991) Diel, lunar and seasonal changes in a mangrove fish assemblage off southwestern Puerto Rico. Bull Mar Sci 49:684-698

Sale PF, Doherty PJ, Eckert GJ, Douglas WA, Ferrell DJ (1984a) Large scale spatial and temporal variation in recruitment to fish populations on coral reefs. Oecologia 64:191-198

Sale PF, Douglas WA, Doherty PJ (1984b) Choice of microhabitats by coral reef fishes at settlement. Coral Reefs 3: 91-99

Sale PF, Ferrell DJ (1988) Early survivorship of juvenile coral reef fishes. Coral Reefs 7:117-124

SAS (1990) SAS/STAT Software Version 6. SAS Institute, Cary, NC

Shulman MJ (1985) Recruitment of coral reef fishes: effects of distribution of predators and shelter. Ecology 66: $1056-1066$

Shulman MJ, Ogden JC (1987) What controls tropical reef fish populations: recruitment or benthic mortality? An example in the Caribbean reef fish Haemulon flavolineatum. Mar Ecol Prog Ser 39:233-242

Stobutzki IC, Bellwood DR (1994) An analysis of the sustained swimming abilities of pre- and post-settlement coral reef fishes. J Exp Mar Biol Ecol 175:275-286

Sweatman H (1985a) The timing of settlement by larval Dascyllus aruanus: some consequences for larval habitat selection. Proc 5th Int Coral Reef Congr 5:367-371

Sweatman H (1985b) The influence of adults of some coral reef fishes on larval recruitment. Ecol Monogr 55:469-485

Sweatman H (1988) Fleld evidence that settling coral reef fish larvae detect resident fishes using dissolved chemical cues. J Exp Mar Biol Ecol 124:163-174

Sweatman H, Robertson DR (1994) Grazing halos and predation on juvenile Caribbean surgeonfishes. Mar Ecol Prog Ser 111:1-6

Sweatman H, St John J (1990) Effects of selective settlement and of aggression by residents on distribution of young recruits of two tropical damselfishes. Mar Biol 105: $247-252$

Victor BC (1986a) Larval settlement and juvenile mortality in a recruitment-limited coral reef fish population. Ecol Monogr 56:145-160

Victor BC (1986b) Delayed metamorphosis with reduced larval growth in a coral reef fish. Thalassoma bifasciatum. Can J Fish Aquat Sci 43:1208-1213

Wellinglon GM (1992) Habitat selection and juvenile persistence control the distribution of two closely related Caribbean damselfishes. Oecologia 90:500-508

Williams DMcB (1980) Dynamics of the pomacentrid community on small patch reefs in One Tree Lagoon (Great Barrier Reef). Bull Mar Sci 30:159-170

Williams DMCB, Sale PF (1981) Spatial and temporal patterns of recruitment of juvenule coral reef fishes to coral habitats within 'One Tree Lagoon', Great Barrier Reef. Mar Biol 65:245-253

Manuscript first received: July 18, 1996

Revised version accepted: February 18, 1997 